\title{
Relationship between functional capacity and the occurrence of adverse events during healthcare utilization
}

\author{
Dijana Babić1,2*, Danica Železnik³ ${ }^{3}$ Milan Miloševićc
}

${ }^{1}$ Clinic for Cardiovascular Diseases Magdalena, Krapinske Toplice, Croatia, ${ }^{2}$ Department for Social Gerontology, University Alma Mater Europea Maribor, Slovenia, ${ }^{3}$ Faculty of Health and Social Sciences Slovenj Gradec, Slovenia, ${ }^{4}$ School of Medicine, University of Zagreb - Andrija Štampar School of Public Health, Zagreb, Croatia

\begin{abstract}
Introduction: Adverse events, safety incidents, and medical errors in healthcare can be avoided only by understanding the causes of their occurrence, and by applying the knowledge gained from the analysis of similar previous events. Since it is known that most adverse events do not originate from a single cause, most important is timely identification of numerous contributory states that can give us the opportunity to define a number of possible solutions to correct process errors and deficiencies in the system itself. The aim of this paper is to investigate the association between functional capacity of elderly living with cardiovascular diseases and the occurrence of adverse events during use of health-care services.

Methods: Assessment of functional limitations was done using the Groningen Activity Restriction Scale (GARS). The presence of adverse events was evaluated after interviews with subjects and review of medical records. Differences in continuous numerical values between inpatient and outpatient service users were analyzed by the Mann-Whitney U-test. Spearman's correlation coefficients of the number of actual adverse events with the presence of restrictions in daily activities were calculated. Fisher's exact test or Fisher-Freeman-Halton test (in cases of table sizes larger than $2 \times 2$ format) analyzed the differences in category variables.
\end{abstract}

Results: The total number of adverse events was 30 (10.1\% of the total number of subjects), while there were 12 actual adverse events (40.0\% of the total number of adverse events). No statistically significant correlation was found between the limitations in performing daily activities and the occurrence of actual adverse events $(p=0.173)$.

Conclusion: The research conducted in this paper showed that the functional capacity of the elderly with chronic disease is not exclusively related with the occurrence of adverse events associated with health-care utilization.

Keywords: Functional capacity; elderly; adverse events; healthcare

\section{INTRODUCTION}

The process of aging is characterized with the presence of multiple changes in the physical, mental, and social functioning of a person (1-4). These changes are often reflected in the appearance of limitations in performing normal daily self-care activities. Therefore, one of the often used method for the assessment of persons functional status in old age is measurement of difficulties in performing basic daily activities such as eating, dressing, moving, maintaining hygiene and going to the toilet, and instrumental daily activities such as preparing meals, buying groceries, doing household chores, and managing finances $(5,6)$. Almost $20-25 \%$ of people over the age of 65 report difficulties

*Corresponding author: Dijana Babić, Clinic for Cardiovascular Diseases Magdalena, Krapinske Toplice, Croatia, partment for Social Gerontology, University Alma Mater Europea Maribor, Slovenia. E-mail: dijana.babic55@ gmail.com

Submitted: 13 December 2020/Accepted: 09 June 2021

in performing basic daily activities (7). Consequently, the focus of care for the elderly persons today is turned to development strategies and specific measures aimed to slow or prevent the onset and progression of functional impairment (8).

Impairment of functional capacity is influenced by a number of factors, among which, in addition to age, most important are the occurrence of chronic diseases, especially comorbidities, cognitive impairment, sensory losses, low level of physical activity, reduced social contacts, depression, smoking, and poor self-esteem $(9,10)$. Health conditions that can significantly affect the occurrence of functional limitations are primarily chronic cardiovascular and respiratory diseases, diabetes, neurological disorders, tumors, obesity, dementia, behavioral changes, sensory losses, and fractures (11-13). Accumulation of chronic diseases and multiple health conditions in the elderly often represents a turning point that leads to a progressive loss of resistance to external influences and disruption of the homeostasis of organism (14). Multimorbidity is defined 
as the presence of two or more chronic diseases and conditions simultaneously that cannot be completely cured but can be controlled by medication and other treatments (15-17). People with multimorbidity have significantly reduced functional capacity, poorer quality of life, higher mortality rates, and more intensive need for use of health-care services then healthy individuals or those with only one chronic condition (18).

One of the significant problems that seriously compromise the safety of the elderly while receiving healthcare is the occurrence of adverse events and medical errors (19-22). Based on numerous studies conducted so far on this field it can be said that every patient who was faced to a certain adverse effect or outcome resulting from medical treatment has actually experienced an adverse event (23). An adverse event is defined as an unintentional injury or complication that results from medical procedures and has caused measurable damage in the form of disability, prolonged hospital stay, severe damage to health, or death $(20,24-32)$. Adverse events most commonly occur as a result of surgical procedures, medication administration, nosocomial infections, technical problems, and lack of patient assessment and monitoring (31,33-35).

Adverse events are more frequently present among elderly patients, who also have the largest share in the number of hospital admissions (36). The reasons for this phenomenon are found in the fact that healthcare for the elderly can be more complex and demanding, often including longer hospitalizations, treatment with numerous medications and exposure to multiple medical procedures, while physiological compensatory mechanisms are naturally decreased $(14,24,37)$. Significant risk factors contributing to the occurrence of adverse events in hospitalized elderly persons, in addition to age, are the complexity of the clinical condition and severity of the disease, presence of comorbidities, reduced functional capacity, and poor quality of care (21).

Adverse events that occur during health-care utilization are often very difficult to recognize and characterize, especially in patients who have a number of previously identified health and other problems, non-specific disease presentations, and limited ability to communicate and participate in treatment (21). Since there is no characteristic risk profile for the detection of patient's particularly prone to adverse events, it can be considered that there is a certain risk in every hospitalized elderly patient (20).

Adverse events, safety incidents, and medical errors in healthcare can be avoided only by understanding the causes of their occurrence, and by applying the knowledge gained from the analysis of similar previous events (38). Since it is known that most adverse events do not originate from a single cause, most important is timely identification of numerous contributory states that can give us the opportunity to define a number of possible solutions to correct process errors and deficiencies in the system itself (38). Therefore, the aim of this study is to determine the frequency and type of adverse events that occur during the use of health services, and their possible relationship with the decrease of functional capacity in the elderly with chronic cardiovascular disease.

\section{METHODS}

The study was conducted on a sample of 298 randomly selected subjects equally divided in groups of outpatient and inpatient services users. Inclusion criteria were age (>65 years), history of at least one chronic cardiovascular disease, ability to participate in a telephone interview, and written consent to participate in the study. For the group of subjects who used inpatient services, an additional criterion was discharge from hospital treatment in the period from 10 days to 2 weeks before the data collection, while for the group of subjects who used outpatient services the same criterion was absence of any form of hospital treatment in a period of minimum 3-6 months before inclusion in the study. Subjects were selected on daily basis by trained nurses from the pool of admitted patients based on inclusion criteria and willingness to participate in the study. Each subject was provided with information about aim of the study and methodology of collecting data.

Data were collected using the follow-up telephone interview provided by trained nurses, retrospective review of medical records, and analysis of collected adverse event reports. Study was approved by a suitably constituted Ethics Committee of the Clinic for Cardiovascular Diseases Magdalena and it conformed to the provisions of the Declaration of Helsinki in 1995 (as revised in Edinburgh 2000).

A structured questionnaire was used to collect data on socio-demographic parameters. Data on medical status were collected by reviewing medical records in the hospital information system. Data on emerging health problems and discharge difficulties were collected using a structured follow-up template (39) that contains open-ended questions about current health status and emerging health problems, problems with taking medication, availability of appointments for control visits, treatment in case of new health problems, and additional difficulties.

Groningen Activity Restrictions Scale (GARS) was used for assessment of present limitations in daily activities performance (40). This scale is an previously validated instrument based on the self-assessment of the limitation in performance of basic (ADL) and instrumental activities of daily living (IADL). The scale consisted of 18 closedended questions, of which 11 relate to the assessment of the performance of basic daily activities and seven to the assessment of the performance of instrumental daily activities. The total number of points that can be achieved by applying this scale ranges from 18 to 72 , with a higher total number of points indicating a higher level of limitations in performing daily activities.

Validation of the scale was first described by Kempen et al. (1996) in their study conducted on a sample of elderly people who showed that the Groningen scale is a comprehensive, valid, reliable, and simple tool for assessing limitations in performing daily activities with high internal reliability for subjects of both sexes (0.89-0.92). Similar characteristics of this scale were originally showed in a study by Suurmeijer et al. (1994) conducted on a group of patients with rheumatoid arthritis whose results support a high degree of internal reliability of this scale $($ rho $=0.94)$ and 
applicability in comparative and longitudinal studies in different environments.

Data on the presence of adverse events were collected by completing an adverse event report whose presence was observed by the examiners during a telephone interview. The questionnaire is based on a template available in the literature $(41,42)$ which, after linguistic and conceptual validation, was adapted for application on a selected group of subjects. Completed adverse event reports were reviewed by a team of experts (specialist physician, clinical pharmacist, and registered nurse) based on whose consensus they were differentiated into groups of confirmed and possible adverse events.

This research was designed as cross-sectional study conducted in three phases in the period from May 1 to October 15, 2019, in Clinic for Cardiovascular Diseases Magdalena. The first phase consisted of the selection and recruitment of subjects who met the inclusion criteria. All subjects were informed about the purpose and goal of the research, ways to conduct it, and the possibility of withdrawal. All subjects expressed their informed written consent to participate. The second phase of the research consisted from a conducting telephone interview with selected subjects. The interview was provided by trained call center nurses in a two parts. The first part of this interview was conducted with the aim of collecting data on the presence of limitations in performing daily activities by application of the GARS scale. The second part of the interview was focused on collecting data on the presence of adverse events using a structured follow-up questionnaire designed to monitor the patient after discharge from treatment. During this part of the interview, the nurses recorded information obtained from the subjects regarding the existing health condition, the presence of emerging difficulties, and the course of recovery as well as additional needs for medical or other assistance if any.

The third phase of the research consisted of a review of all collected reports obtained during telephone interviews. Those reports that referred to any health problem or emerging difficulty currently present at the subjects were singled out. Based on these data, adverse event reports were completed. All selected reports were reviewed by an expert team consisting of a professional nurse, a cardiologist, and a clinical pharmacist. Based on the analysis and opinion of the expert team, and a review of available medical documentation, the reports were selected into groups of potential and actual adverse events. Data suggesting the presence of an adverse event were selected from the reports based on common characteristics according to the template of Okoniewska et al. (2016) and classified into the following groups: Adverse drug reaction, injury due to medical procedure, infection, fall, error in therapeutic procedures, communication or organizational problem, diagnostic error, and others.

The data are presented in tables and figures. The distribution of continuous data was analyzed by the SmirnovKolmogorov test, and according to the obtained results, appropriate non-parametric tests were applied in further analysis. Differences in continuous numerical values between inpatient and outpatient service users were analyzed by the Mann-Whitney U-test. Spearman's correlation coefficients of the number of actual adverse events with the presence of restrictions in daily activities were calculated. Fisher's exact test or Fisher-FreemanHalton test (in cases of table sizes larger than $2 \times 2$ format) analyzed the differences in category variables. The Cronbach's $\alpha$ coefficient of internal consistency for the GARS scale was calculated. All $p<0.05$ were considered significant. IBM SPSS Statistics software, version 25.0 was used in the analysis.

\section{RESULTS}

Descriptive statistics of continuous clinical values are shown in Table 1 . The median age (interquartile range) of subjects was $72.0(68.0-76.0)$ years. The median number of different diagnoses was $6.0(5.0-8.0)$ and the number of medications the subjects were taking was 8.0 (5.0-10.0). The median value of the GARS scale was 18.0 (18.0-27.0).

Assessment of the ability to perform daily activities in elderly with cardiovascular disease shown that the majority of subjects (more than 75\%) perform basic daily activities (ADL) completely independently. Subjects most often reported a certain level of difficulty for climbing up and down the stairs $(\mathrm{N}=69 ; 23.1 \%)$, and for walking outside the household $(\mathrm{N}=54 ; 18.1 \%)$. When assessing the ability to perform instrumental daily activities (IADL), the reported level of independence is somewhat lower, with the smallest share of fully independent performance of activities present in performing difficult household chores. In this group of instrumental daily activities, a total of $38.3 \%$ of subjects reported difficulties $(\mathrm{N}=104)$. Of the other instrumental activities, difficulties often occur in maintaining laundry hygiene $(\mathrm{N}=101 ; 34.0 \%)$, as well as when going shopping $(\mathrm{N}=90 ; 30.2 \%)$. The correlation of age with the ability to perform daily activities shows a significant positive correlation ( $r h o=0.313 ; p<0.001$ ) between age and results achieved on the GARS scale (older age - higher values on the scale) only in subjects who used inpatient services. Comparison of the total number of points achieved on the GARS scale with the total number of diagnoses and medications in two groups of subjects showed the presence of a statistically significant positive correlation $(p=0.000$ and $p=0.001$ ) between these variables in subjects who used inpatient services, while in those who used outpatient services this correlation was positive only in the relationship between the results on the GARS scale and the total number of medications ( $p=0.001$; Rho 0.26).

The ratio of exposure to a particular type of treatment and the occurrence of any adverse event in the elderly with cardiovascular disease is shown in Table 2 . The total number of reported adverse events in the total sample was 30 (10.1\%). A significantly higher number of reported adverse events was recorded in the sample of subjects who used inpatient services (14.6\%), while only $8(5.4 \%)$ adverse events were reported in the group of subjects who used outpatient services. Fisher's exact test confirmed the existence of a statistically significant difference in the incidence of reported adverse events between these two groups of subjects $(p=0.012)$, which suggests consideration of the impact of a specific environment on the occurrence of adverse events during health care utilization. Calculation of correlation 
TABLE 1. Descriptive statistics of continuous clinical variables

\begin{tabular}{lcccc}
\hline & $\mathrm{N}$ & \multicolumn{3}{c}{ Centile } \\
\cline { 3 - 5 } & & 25. & Median & 75. \\
\hline Total number of medical diagnosis & 298 & 5,00 & 6,00 & 8,00 \\
Total number of medications & 298 & 5,00 & 8,00 & 10,00 \\
Length of stay (days) & 151 & 2,00 & 3,00 & 3,00 \\
Age (years) & 298 & 68,00 & 72,00 & 76,00 \\
GARS & 298 & 18,00 & 18,00 & 27,00 \\
\hline
\end{tabular}

Source: BIS system of the Clinic for Cardiovascular Diseases "Magdalena" and Groningen activity restrictions scale 2019

TABLE 2. Relationship between exposure to a particular type of treatment and the occurrence of adverse event: Fisher's exact test

\begin{tabular}{|c|c|c|c|c|c|}
\hline & & & $\begin{array}{r}\text { Actua } \\
\mathrm{e}\end{array}$ & $\begin{array}{l}\text { adverse } \\
\text { ents }\end{array}$ & Total \\
\hline & & & No & Yes & \\
\hline $\begin{array}{l}\text { Group } \\
\text { Inpatients }\end{array}$ & & & & & \\
\hline $\mathrm{N}$ & & & 143 & 8 & 151 \\
\hline$\%$ & & & $94,7 \%$ & $5,3 \%$ & $100,0 \%$ \\
\hline Outpatients & & & & & \\
\hline $\mathrm{N}$ & & & 143 & 4 & 147 \\
\hline$\%$ & & & $97,3 \%$ & $2,7 \%$ & $100,0 \%$ \\
\hline Total & & & & & \\
\hline $\mathrm{N}$ & & & 286 & 12 & 298 \\
\hline$\%$ & & & $96,0 \%$ & $4,0 \%$ & $100,0 \%$ \\
\hline & Value & df & $P$ & $\begin{array}{l}\text { Exact } P \\
\text { (2-sided) }\end{array}$ & $\begin{array}{l}\text { Exact } P \\
\text { (1-sided) }\end{array}$ \\
\hline $\begin{array}{l}\text { Pearson } \\
\text { Chi-Square }\end{array}$ & $1,280^{\mathrm{a}}$ & 1 & 0,258 & & \\
\hline $\begin{array}{l}\text { Fisher's Exact } \\
\text { Test }\end{array}$ & & & & 0,378 & 0,202 \\
\hline $\begin{array}{l}\text { Linear- } \\
\text { by-Linear } \\
\text { Association }\end{array}$ & 1,276 & 1 & 0,259 & & \\
\hline $\begin{array}{l}N \text { of Valid } \\
\text { Cases }\end{array}$ & 298 & & & & \\
\hline
\end{tabular}

Source: Own source 2019.

coefficients for the number of actual adverse events and the estimated ability to perform daily activities show that there was no statistically significant correlation between these parameters. This assumes that the reduced ability to perform daily activities does not have a significant impact on the occurrence of adverse events in the elderly with chronic cardiovascular disease.

The description of all recorded adverse events is shown in Table 3. Among total number of recorded adverse events $(\mathrm{N}=30,10,1 \%)$ more than half were declared as actual adverse events $(\mathrm{N}=18,60 \%)$. As actual adverse events predominantly recorded were those related to administration of drugs $(\mathrm{N}=5 ; 41.7 \%)$. A quarter of the other actual adverse events were injuries due to medical procedure and possible errors in therapeutic procedures $(\mathrm{N}=3,25 \%)$. Furthermore, there was one case of an adverse event that could not be classified $(\mathrm{N}=1,8,3 \%)$. The time of occurrence of actual adverse events in most cases $(\mathrm{N}=9 ; 75.0 \%)$ was in the morning from 6 to $12 \mathrm{AM}$, while reported place of occurrence in the majority cases $(\mathrm{N}=9 ; 75.0 \%)$ was home. The specific circumstance of their occurrence, in an equal number of cases was the time during taking the prescribed therapy. The consequences of an actual adverse event were present in $11(91.7 \%)$ cases.
TABLE 3. Description of recorded adverse events

\begin{tabular}{lcc}
\hline & $\mathrm{N}$ & $\%$ \\
\hline Potential adverse events & & $89,9 \%$ \\
No & 268 & $10,1 \%$ \\
Yes & 30 & \\
Actual adverse events & & \\
Ne & 18 & $60,0 \%$ \\
Da & 12 & $40,0 \%$ \\
Description of actual adverse events & & \\
Adverse drug reaction & 5 & $41,7 \%$ \\
Injury related to medical procedure & 3 & $25,0 \%$ \\
Infection & 0 & $0,0 \%$ \\
Fall & 0 & $0,0 \%$ \\
Errors related to therapeutic procedures & 3 & $25,0 \%$ \\
Communication problem & 0 & $0,0 \%$ \\
Diagnostic error & 0 & $0,0 \%$ \\
$\quad$ Other & 1 & $8,3 \%$ \\
\hline
\end{tabular}

Source: Own source 2019

TABLE 4. Differences in the type of actual adverse events: FisherFreeman-Halton test

\begin{tabular}{|c|c|c|c|c|c|}
\hline \multirow{3}{*}{\multicolumn{2}{|c|}{$\begin{array}{l}\text { Fisher-Freeman- } \\
\text { Halton test; } P=0,545\end{array}$}} & \multicolumn{4}{|c|}{ Group } \\
\hline & & \multicolumn{2}{|c|}{ Inpatients } & \multicolumn{2}{|c|}{ Outpatients } \\
\hline & & $\%$ & $\mathrm{~N}$ & $\%$ & $\mathrm{~N}$ \\
\hline \multirow{9}{*}{$\begin{array}{l}\text { Type of adverse } \\
\text { event }\end{array}$} & None & 0 & $0,0 \%$ & 0 & $0,0 \%$ \\
\hline & $\begin{array}{l}\text { Adverse drug } \\
\text { reaction }\end{array}$ & 3 & $37,5 \%$ & 2 & $50,0 \%$ \\
\hline & $\begin{array}{l}\text { Injury due medical } \\
\text { procedure }\end{array}$ & 3 & $37,5 \%$ & 0 & $0,0 \%$ \\
\hline & Infection & 0 & $0,0 \%$ & 0 & $0,0 \%$ \\
\hline & Fall & 0 & $0,0 \%$ & 0 & $0,0 \%$ \\
\hline & $\begin{array}{l}\text { Error in therapeutic } \\
\text { procedures }\end{array}$ & 1 & $12,5 \%$ & 2 & $50,0 \%$ \\
\hline & $\begin{array}{l}\text { Communication } \\
\text { problem }\end{array}$ & 0 & $0,0 \%$ & 0 & $0,0 \%$ \\
\hline & Diagnostic error & 0 & $0,0 \%$ & 0 & $0,0 \%$ \\
\hline & Other & 1 & $12,5 \%$ & 0 & $0,0 \%$ \\
\hline
\end{tabular}

Source: Own source 2019

Differences in the type of actual adverse events occurring in different health-care environments are shown in Table 4. In the group of subjects who used inpatient services, the most frequently present adverse events were adverse drug reactions $(37.5 \%)$, injuries due to medical procedures (37.5\%), and errors in prescribing therapy (12.5\%). In subjects who used outpatient services, equal proportions of actual adverse events consisted of adverse drug reactions (50\%) and errors in therapeutic procedures $(50 \%)$. The analysis of the difference in the number of adverse events showed that it exists only in the case of consideration of all reported potential adverse events. However, no statistical difference was found in the number of actual adverse events. As confirmed by Fisher's exact test, the number of actual adverse events did not differ with statistical significance $(p=0.378)$ in the two groups of subjects. Nevertheless, it is important to note that there were twice as many of them in the group of patients who used inpatient services, and it can be assumed that a possible higher number of reported adverse events would increase the statistically significant difference between these groups of subjects.

Table 5 shows the relationship between actual adverse events and their prevention options. As can be seen from the presented data, consequences of actual adverse events 
TABLE 5. Overview of the relationship between actual adverse events and prevention options

\begin{tabular}{lcccc}
\hline Mitigating & \multicolumn{3}{c}{ Event type } & Total \\
\cline { 2 - 4 } & Preventive & None & \\
\hline Actual adverse events & & & 3 & 12 \\
$\mathrm{~N}$ & 9 & 0 & 3 & $12 \%$ \\
$\%$ & $75,00 \%$ & $0,00 \%$ & $25,00 \%$ & $100,00 \%$ \\
\hline
\end{tabular}

were present in $11(91.7 \%)$ cases, and the events were mitigated in $9(75.0 \%)$ cases, while none were preventable.

\section{DISCUSSION}

The results of the study confirmed a previously known fact about mutual influence of variety of factors on the decline of functional capacity among elderly persons with chronic diseases. Our study was shown positive correlation between functional limitations and age only in subjects who used inpatient services. These data lead to presumption that the severity of the chronic disease which requires hospital treatment and are often reflected in the number of comorbidities and medications necessary to control the disease have significantly negative impact on functional capacity in elderly patients. In their study, Hajek and König (2016) (43) describe an expanded range of factors that, with increasing age, affect the progressive decline in the functional capacity of the elderly, among which the occurrence of depression and cognitive impairment, the number of chronic conditions, regular alcohol consumption, smoking, and life in single household are particularly relevant. In recent decades, research has focused on the impact of multimorbidity on the health and quality of life of the elderly, mainly driven by the fact that as many as $70 \%$ of people over the age of 70 face this problem (44). Multimorbidity inevitably leads to functional and physical impairment, with individuals suffering from multiple chronic diseases and conditions simultaneously exposed to a faster decline in functional capacity (44). Study by St. John et al. (2019) conducted on a sample of elderly people living independently in a community confirmed that future functional impairment can be predicted based on the presence of multimorbidity, but at the same time did not offer clarification of the mechanisms that cause it. However, the authors confirmed that multimorbidity occurs with increasing age, with females of the lower level of education, cognitive difficulties, and pronounced depressive symptoms being particularly exposed to it $(45)$.

The assessment of restrictions in daily activities showed that they are present mainly in the performance of those tasks that require the preservation of motor functions, mobility, and endurance of a certain higher level of physical effort. A study by Kleipool et al. (2018) showed that the existence of cardiovascular disease in old age (46), especially peripheral arterial disease and heart failure, almost doubles the risk of developing frailty syndrome, especially its incidence, compared to other chronic diseases such as are lung disease, arthritis or diabetes. The presence of multimorbidity in old age almost doubles the need for physician contact, hospital admissions, and specialized healthcare (47). On the other hand, the occurrence of acute health conditions in the elderly is strongly associated with the occurrence of adverse outcomes, with the majority of acutely hospitalized elderly being also multimorbid (48).

Although the results of our study showed that no statistically significant association was found between the functional capacity of subjects and the occurrence of adverse events, the study clearly showed that the functional capacity of subjects who used inpatient services was significantly lower, which can be partially explained due the impact and severity of the actual health status. This result implies that persons undergoing hospital treatment are those whose health condition is seriously impaired. Therefore, such persons have a higher risk of decline in functional capacity, but also the occurrence of numerous difficulties in the recovery period. The study by Ruiz et al. (2015) confirmed that multimorbidity is highly prevalent and present in almost $67.5 \%$ of people admitted to hospital (49), with its frequency increasing with increasing age of $56 \%$ in people over 65 to $67 \%$ in people older of 80 years making their condition particularly complex. Numerous previous studies have indicated a strong association between multimorbidity and the occurrence of adverse events, especially those resulting from the use of a multiple medications (50-54). A retrospective review of medical records conducted by Wang et al. (2016) showed that, in addition to old age, the most important risk factors for medical adverse events during hospital treatment were the complexity of the patient's health, primarily the presence of heart disease, complications caused by treatment, especially surgical procedures, and previous hospital admissions. The recorded incidence of adverse medical events in this study was only $0.7 \%$ which is explained by the existence and increasing implementation of standardized hospital safety protocols and procedures that affect omission reduction in normal daily patient care (55).

The results of our study showed a difference in the incidence of certain types of adverse events between the two groups of subjects. It is clear that in both groups the most commonly recorded events were adverse drug reactions or errors in their use. Nevertheless, a group of subjects who used inpatient services also recorded errors that occurred as a result of diagnostic or therapeutic procedures. A study by Woods et al. (56) showed a fairly diverse range of adverse events identified in outpatient care, from missed or delayed diagnoses $(36 \%)$, post-surgery events $(24.1 \%)$, non-surgical procedures (14.6\%), medication (13.1\%), and therapeutic events (12.3\%). However, a recent study conducted by Geraedts et al. (57) using the methodology of telephone interviews of outpatient users showed that the most common areas where safety problems occur were diagnostic procedures (61\%) and medication (15\%). Results similar to ours were shown by a review study provided by Schwendimann et al. (58) which found that three types of adverse events most commonly occur in hospital settings: Consequences of operative or surgical procedures, side effects or errors in medication or infusion application, and infections associated with healthcare. The findings of our study and previously published studies show considerable similarities, but also differences in the types of adverse events that occur in health-care settings, which can be explained by the specifics of each group of patients and characteristics of each health-care provider. It is important to emphasize that our study found a dominant frequency of 
side effects and omissions in the use of medication, which is significant and noteworthy given the multiple medication use often present by patients with chronic cardiovascular disease.

Similar findings were shown by the study by De Vries et al. (2008), according to which the causes of adverse events are most often associated with medical procedures (39.6\%) and the effects of medications (15.1\%), while the study by Ohta et al. (59), in addition to the consequences of the use of multiple medications, also underline events such as bleeding due to therapeutic interventions. Exposure to complex medical treatments for chronic health conditions certainly contributes an increased risk of adverse events resulting from receiving health services. Our study shows that each particular type of treatment carries a share of the risk of specific adverse events or omissions in care that is important to pay attention to, especially for reasons of possible prevention of their occurrence.

Despite discussions in the literature about methodological limitations in the assessment of preventable adverse events, the results of a study by Martins et al. (60) show that their prevalence is significant, while outcomes can be seriously harmful consequences and even patient death. According to a review study conducted by Schwendimann et al. (2018), adverse events are present in the range of $2.9 \%$ to $21.9 \%$ of all hospital admissions, of which $34.3 \%$ to $83 \%$ are considered preventable. As noted by Forster et al. (61) patients may be particularly vulnerable to the occurrence of adverse events and injuries in the post-hospital discharge period, as functional limitations associated with hospitalization may still be present, as well as a possible gap in treatment transfer between inpatient and outpatient care. According to a study by Sears et al. (62), a significant proportion of home care users are exposed to adverse events during care $(13.2 \%)$, of which almost a third can be prevented, while a certain proportion $(1.4 \%)$ the same associated with the death of the patient. The occurrence of dependence on the help of others in performing instrumental daily activities and the increase in the number of comorbidities significantly affect the increase in the risk of adverse events in home care $(63,64)$. Our study suggests that the assessment of functional capacity is possibly one of the ways to identify persons prone to difficulties in the recovery period, including adverse events or omissions in care.

The occurrence of adverse events seriously compromises patient safety and the quality of care in hospital settings (58). The results of this study showed that the most of the adverse events reported were mitigating. Such findings differ somewhat from previously published studies, which generally highlight the significant ability to prevent adverse events, especially those arising from the use of medications $(56,58,65-67)$. It is important to emphasize that in our research, the term "mitigating" was presented in the classification of adverse events, along with the term "preventable," which has been mostly used so far. This classification allows clinicians to more clearly determine and more objectively assess the possibility of preventing adverse events, especially in the case of deeper analysis of adverse drug reactions or errors in their application.

Finally, we must point out the limitations that this study had. In the first place, we single out the method of data collection, which has its limitations visible primarily in the difficult possibility of checking their reliability. Furthermore, the assessment of the presence of functional limitations in the respondents may have been influenced by a subjective assessment of the severity of their own health condition and the presence of observed difficulties in recovery, while reducing the level of actual functional capacity. Furthermore, the definition of adverse events by health professionals often encounters obstacles in terms of the existence of numerous interpretations of what they really are and the difficulty of separating them from the expected difficulties, that is, described in the literature possible adverse disease outcomes not related to healthcare.

\section{CONCLUSION}

The natural increase in number and incidence of chronic diseases among elderly persons are the most important reason for frequent use of health-care services in this population. Although we did not establish a statistical correlation between the decrease in functional capacity and the occurrence of adverse events during health-care utilization, this research showed that there is a difference in their incidence among different health-care environments. We emphasize that that elderly people with advanced chronic health problems and expected decline in functional capacity requiring the use of inpatient services are at increased risk of experiencing adverse events. Moreover, this study showed very clearly that a number of adverse events actually cannot be prevented. Therefore, we draw attention to the importance of understanding the complexity of the patient's condition as a contributing factor to adverse events occurrence. We also recommend introduction of measures aimed to monitor and identify different types of adverse events specific to a particular healthcare environment along with raising awareness of their existence as a step toward diminishing negative consequences which they can have on patients and organizations.

\section{CONFLICT OF INTEREST}

The authors declare no conflict of interest.

\section{ACKNOWLEDGMENTS}

We sincerely thank all study participants for taking part in this study as well as to registered nurses for helping in data collection.

\section{REFERENCES}

1. Charles S, Carstensen LL. Social and emotional ageing. Annu Rev Psychol 2010;61:383-409.

2. Dziechciaz M, Filip R. Biological psychological and social determinants of old age: Biopsycho-social aspects of human ageing. Ann Agric Environ Med. 2014;21(4):835-8. https://doi.org/10.5604/12321966.1129943

3. Amarya S, Kalyani S, Sabharwal M. Ageing process and physiological changes. In: D'Onofrio G, Greco A, Sancarlo D, editors. Gerontology: Intech Open; 2018. https://doi.org/10.5772/intechopen.76249

4. Read S, Comas-Herrera A, Grandy E. Social isolation and memory decline in later life. J Gerontol B Psychol Sci Soc Sci 2020;75(2):367-76.

5. Kleinpell RM, Fletcher K, Jennings BM. Reducing functional decline in hospitalized eldery. In: Hughes RG, editor. Patient Safety and Quality. An Evidence-Based Handbook for Nurses. Rockville, MD: Agency for Healthcare Research and Quality, US; 2008.

6. Edemekong PF, Bomgaars DL, Sukumaran S, Levy SB. Activities of daily living. In: 
StatPearls. Treasure Island, FL: StatPearls Publishing; 202

7. Brown RT, Diaz-Ramirez LG, Boscardin WJ, Lee SJ, Steinman MA. Functional impairment and decline in middle age: A cohort study. Ann Intern Med 2017;167(11):761-8. https://doi.org/10.7326/m17-0496

8. Brown RT, Covinsky KE. Moving prevention of functional impairment upstream: Is middle age an ideal time for intervention? Womens Midlife Health 2020;6:4 https://doi.org/10.1186/s40695-020-00054-z

9. Dunlop DD, Semanik P, Song J, Manheim LM, Shih V, Chang RW. Risk factors for functional decline in older adults with arthritis. Arthritis Rheum 2005;52(4):1274-82. https://doi.org/10.1002/art.20968

10. Van der Vorst A, Rixt Zijlstra GA, De Witte N, Duppen D, Stuck AE, Kempen GI et al. Limitations in activities of daily living in community-dwelling people aged 75 and over: A systematic literature review of risk and protective factors. PLoS One 2016;11(10):e0165127

https://doi.org/10.1371/journal.pone.0165127

11. Colon-Emeric C, Whitson HE, Pavon J, Hoenig H. Functional decline in older adults. Am Fam Physician 2013;188(6):388-94.

12. Costa Filho AM, Mambrini JV, Malta DC, Lima-Costa MF, Peixoto SV. Contribution of chronic diseases to the prevalence of disability in basic and instrumantal activities of daily living in elderly-Brazilians: The national health survey (2013). Cad Saude Publica 2018:34(1):e00204016.

https://doi.org/10.1590/0102-311x00204016

13. Vetrano DL, Rizzuto D, Calderon-Larranaga A, Onder G, Welmer AK, Bernabei R et al. Trajectories of functional decline in older adults with neuropsychiatric and cardiovascular multimorbidity: A Swedish cohort study. PLoS Med 2018;15(3):e1002503. https://doi.org/10.1371/journal.pmed.1002503

14. Fabbri E, Zoli M, Gonzalez-Freira M, Salive ME, Studenski SA, Ferrucci L. Ageing and multimorbidity: New tasks, priorities, and frontiers for integrated gerontological and clinical research. J Am Med Dir Assoc 2015;16(8):640-7.

https://doi.org/10.1016/j.jamda.2015.03.013

15. Salive ME. Multimorbidity in older adults. Epidemiol Rev 2013;35(1):75-83.

16. Yarnall AJ, Sayer AA, Clegg A, Rockwood K, Parker S, Hindle JV. New horizons in multimorbidity in older adults. Age Ageing 2017;46(6):882-8.

https://doi.org/10.1093/ageing/afx150

17. Forman DE, Maurer MS, Boyd C, Brindis R, Salive ME, McFarland Horne F, et al. Multimorbidity in older adults with cardiovascular disease. J Am Coll Cardiol 2018;71(19):2149-61.

https://doi.org/10.1016/j.jacc.2018.03.022

18. Frølich A, Ghith N, Schiøtz M, Jacobsen R, Stockmarr A. Multimorbidity, healthcare utilization and socioeconomic status: A register-based study in Denmark. PLoS One 2019;14(8):e0214183.

https://doi.org/10.1371/journal.pone.0214183

19. Institute of Medicine, Committee on Quality of Health Care. Errors in health care: A leading cause of death and injury. In: Kohn LT, Corrigan JM, Donaldson MS, editors. To Err Is Human: Building a Safer Health System. Washington, DC: Institute of Medicine, Committee on Quality of Health Care; 2000. p. 26-42. https://doi.org/10.17226/13084

20. Szlejf C, Farfel JM, Curiati JA, Couto Junior EB, Jacob-Filho W, Azevedo RS. Medical adverse events in elderly hospitalized patients: A prospective study. Clinics (Sao Paulo) 2012;67(11):1247-52 https://doi.org/10.6061/clinics/2012(11)04

21. Long SJ, Brown KF, Ames D, Vincent C. What is known about adverse events in older medical hospital inpatients? A systematic review of the literature. Int J Qual Health Care 2013;25(5):542-54.

https://doi.org/10.1093/intqhc/mzt056

22. Toffoletto MC, Barbosa RL, Andolhe R, Machado de Oliveira E, Duci AJ, Grillo KP. Factors associated with the occurrence of adverse events in critical elderly patients. Rev Bras Enferm 2016;69(6):977-83.

23. Skelly $\mathrm{CL}$, Cassagnol M, Munakomi S. Adverse events. In: StatPearls. Treasure Island, FL: StatPearls Publishing; 2020. Available from: https://www.ncbi.nlm.nih.gov/ books/NBK558963/\#_NBK558963_pubdet. [Last accessed on 2021 Feb 12].

24. Thomas EJ, Brennan TA. Incidence and types of preventable adverse events in elderly patients: Population based review of medical records. BMJ 2000;320(723):741-4. https://doi.org/10.1136/bmj.320.7237.741

25. Vincent C, Graham N, Woloshynowych M. Adverse events in British hospitals: Preliminary retrospective record review. BMJ 2001;322(7285):517-9.

https://doi.org/10.1136/bmj.322.7285.517

26. Baker GR, Norton PG, Flintoft V, Blais R, Brown A, Cox J, et al. The Canadian adverse events study: The incidence of adverse events among hospital patients in Canada. CMAJ 2004;170(11):1678-86.

https://doi.org/10.1503/cmaj.1040498

27. Grober ED, Bohnen JM. Defining medical error. Can J Surg 2005;48(1):39-44

28. Olsen S, Neale G, Schwab K, Psaila B, Patel T, Chapman EJ, et al. Hospital staff should use more than one method to detect adverse events and potential adverse events: Incident reporting, pharmacist surveillance and local real-time record review may all have a place. Qual Saf Health Care 2007:16:40-4.

https://doi.org/10.1136/qshc.2005.017616

29. Aranaz-Andres JM, Aibar C, Limon R, Mira JJ, Vitaller J, Agra Y, et al. A study of the prevalence of adverse events in primary healthcare in Spain. Eur $\mathrm{J}$ Public Health 2012;22(6):921-5.

https://doi.org/10.1093/eurpub/ckr168

30. Garrouste-Orgeas M, Philippart F, Bruel C, Max A, Lau N, Misset B. Overview of medical errors and adverse events. Ann Intensive Care 2012;2:2. https://doi.org/10.1186/2110-5820-2-2

31. Nilsson L, Risberg MB, Montgomery A, Sjödahl R, Schildmeijer K, Rutberg $H$ Preventable adverse events in surgical care in Sweden: A nationwide review of patient notes. Medicine (Baltimore) 2016;95(11):e3047. https://doi.org/10.1097/md.0000000000003047

32. Davis J, Harrington N, Bittner Fagan H, Henry B, Savoy M. The accuracy of trigger tools to detect preventable adverse events in primary care: A systematic review. J Am Board Fam Med 2018;31(1):113-25. https://doi.org/10.3122/jabfm.2018.01.170247

33. De Vries EN, Ramrattan MA, Smorenburg SM, Gouma DJ, Boermeester MA. The incidence and nature of in-hospital adverse events: A systematic review. Qual Sa Health Care 2008:17(3):216-23. https://doi.org/10.1136/qshc.2007.023622

34. Department of Health and Human Services USA, Office of Inspector General. Adverse Events in Hospitals: National Incidence Among Medicare Beneficiaries; 2010. Available from: https://oig.hhs.gov/oei/reports/oei-06-09-00090.pdf. [Last accessed on 2019 Nov 21]

35. Tsang C, Bottle A, Majeed A, Paul A. Adverse events recorded in English primary care: Observational study using general practice research database. Br J Gen Pract 2013;63(613):e534-42.

https://doi.org/10.3399/bjgp13×670660

36. Borenstein J, Aronow HU, Bolton LB, Choi J, Bresee C, Braunstein GD. Early recognition of risk factors for adverse outcomes during hospitalization among medicare patients: A prospective cohort study. BMC Geriatr 2013;13:72 https://doi.org/10.1186/1471-2318-13-72

37. Singh I. Assessment and management of older people in the general hospital setting. In: Zawada ET Jr., editor. Challenges in Elder Care. India: IntechOpen; 2016. p. 37-68. https://doi.org/10.5772/64294

38. Sanchez JA, Lobdell KW, Moffatt-Bruce SD, Fann JI. Investigating the causes of adverse events. Ann Thorac Surg 2017:103:1693-99. https://doi.org/10.1016/j.athoracsur.2017.04.001

39. Agency for Healthcare Research and Quality. Postdischarge Follow up Phone Call Script (Patient Version); 2013. Available from: https://www.ahrq.gov/patient-safety/ settings/hospital/hai/red/toolkit/postdischarge-phone.html. [Last accessed on 2019 Nov 15].

40. Suurmeijer TP, Doeglas DM, Moum T, Briancon S, Krol B, Sanderman R, et al. The groningen activity restriction scale for measuring disability: Its utility in international comparisons. Am J Public Health 1994;84(8):1270-73. https://doi.org/10.2105/ajph.84.8.1270

41. Kempen GI, Miedma I, Ormel J, Molenar W. The assessment of disability with the Groningen activity restriction scale. Conceptual framework and psychometric properties. Soc Sci Med 1996;43(11):1601-10. https://doi.org/10.1016/s0277-9536(96)00057-3

42. Okoniewska B, Santana MJ, Holroyd-Leduc J, Flemons W, O'Beirne M, White D, et al A framework to assess patient-reported adverse outcomes arizing during hospitalization. BMC Health Serv Res 2016:16:357. https://doi.org/10.1186/s12913-017-2392-z

43. Hajek A, König HH. Longitudinal predictors of functional impairment in older adults in Europe-evidence from the survey of health, ageing and retirement in Europe. PLoS One 2016;11(1):e0146967. https://doi.org/10.1371/journal.pone.0146967

44. Calderon-Larranaga A, Vetrano DL, Ferrucci L, Mercer SW, Marengoni A, Onder G et al. Multimorbidity and functional impairment-bidirectional interplay, synergistic effects and common pathways. J Intern Med 2019;285(3):255-71. https://doi.org/10.1111/joim.12843

45. St John P, Tyas SL, Menec V, Tate R, Griffith L. Multimorbiditiy predicts functional decline in community-dwelling older adults: Prospective cohort study. Can Fam Physician 2019:65(2):e56-63.

46. Kleipool EE, Hoogendijk EO, Trappenburg MC, Handoko ML, Huisman M, Peters MJ, et al. Frailty in older adults with cardiovascular diseases: Cause, effect or both? Aging Dis 2018:9(3):489-97. https://doi.org/10.14336/ad.2017.1125

47. Bähler $C$, Huber $C A, B$ rüngger $B$, Reich $O$. Multimorbidity, health care utilization and costs in an elderly community-dwelling population: A claims data based observational study. BMC Health Serv Res 2015;15:23. https://doi.org/10.1186/s12913-015-0698-2 
48. Juul-Larsen HG, Christensen LD, Bandholm T, Andersen O, Kallemose T, Jørgensen LM, et al. Patterns of multimorbidity and differences in healthcare utilization and complexity among acutely hospitalized medical patients ( $\geq 65$ Years)-a latent class approach. Clin Epidemiol 2020;12:245-59.

https://doi.org/10.2147/clep.s226586

49. Ruiz M, Bottle A, Long S, Aylin P. Multi-morbidity in hospitalised older patients: Who are the complex elderly? PloS One 2015;10(12):e0145372. https://doi.org/10.1371/journal.pone.0145372

50. Calderón-Larrañaga A, Poblador-Plou B, González-Rubio F, Gimeno-Feliu LA, AbadDíez JM, Prados-Torres A. Multimorbidity, polypharmacy, referrals, and adverse drug events: Are we doing things well? Br J Gen Pract 2012;62(605):e821-6. https://doi.org/10.3399/bjgp12x659295

51. Panagioti M, Stokes J, Esmail A, Coventry P, Cheraghi-Sohi S, Alam R, et al. Multimorbidity and patient safety incidents in primary care: A systematic review and meta-analysis. PloS One 2015;10(8):e0135947. https://doi.org/10.1371/journal.pone.0135947

52. Cruz HL, Mota FK, Araújo LU, Bodevan EC, Seixas SR, Santos DF. The utility of the records medical: Factors associated with the medication errors in chronic disease. Rev Lat Am Enferm 2017;25:e2967.

https://doi.org/10.1590/1518-8345.2406.2967

53. Aoki T, Yamamoto Y, Ikenoue T, Onishi Y, Fukuhara S. Multimorbidity patterns in relation to polypharmacy and dosage frequency: A nationwide, cross-sectional study in a Japanese population. Sci Rep 2018;8:3806

https://doi.org/10.1038/s41598-018-21917-6

54. Aoki T, Watanuki S. Multimorbidity and patient-reported diagnostic errors in the primary care setting: Multicentre cross-sectional study in Japan. BMJ Open 2020;10:e039040. https://doi.org/10.1136/bmjopen-2020-039040

55. Wang $\mathrm{CH}$, Shih $\mathrm{CL}$, Chen WJ, Hung SH, Jhang WJ, Chuang LJ, et al. Epidemiology of medical adverse events: Perspective from a single institute in Taiwan. Taiwan Yi Xue Hui Za Zhi 2016;115(6):434-9.

https://doi.org/10.1016/j.jfma.2015.11.004

56. Woods DM, Thomas EJ, Holl JL, Weiss KB, Brennan TA. Ambulatory care adverse events and preventable adverse events leading to a hospital admission. Qual Sa Health Care 2007;16(2):127-31.

https://doi.org/10.1136/qshc.2006.021147

57. Geraedts M, Krause S, Schneider M, Ortwein A, Leinert J, de Cruppe W. Patient safety in ambulatory care from the patient's perspective: A retrospective, representative telephone survey. BMJ Open 2020;10:e034617. https://doi.org/10.1136/bmjopen-2019-034617

58. Schwendimann R, Blatte C, Dhaini S, Simon M, Ausserhofer D. The occurence, types, consequences and preventability of in-hospital adverse events-a scoping review. BMC Health Serv Res 2018;18:521.

https://doi.org/10.1186/s12913-018-3335-z

59. Ohta Y, Miki I, Kimura T, Abe M, Sakuma M, Koike K, et al. Epidemiology of adverse events and medical errors in the care of cardiology patients. J Patient Saf 2019;15(3):251-6

https://doi.org/10.1097/pts.000000000000029

60. Martins M, Travassos C, Mendes W, Pavao AL. Hospital deaths and adverse events in Brazil. BMC Health Serv Res 2011;11:223.

https://doi.org/10.1186/1472-6963-11-223

61. Forster AJ, Murff HJ, Peterson JF, Gandhi TK, Bates DW. The incidence and severity of adverse events affecting patients after discharge from the hospital. Ann Intern Med 2003;138(3):161-7.

https://doi.org/10.7326/0003-4819-138-3-200302040-00007

62. Sears N, Baker GR, Baransley J, Shortt S. The incidence of adverse events among home care patients. Int J Qual Health Care 2013;25(1):16-28.

63. Blais R, Sears N, Doran D, Baker GR, Macdonald M, Mitchel L et al. Assessing adverse events among home care clients in three Canadian provinces using chart review. BMJ Qual Saf 2013;22:989-97.

https://doi.org/10.1136/bmjqs-2013-002039

64. Sears, NA, Blais R, Spinks M, Pare M, Baker GR. Associations between patient factors and adverse events in the home care setting: A secondary data analysis of two canadian adverse event studies. BMC Health Serv Res 2017;17:400.

https://doi.org/10.1186/s12913-017-2351-8

65. Jylhä V, Saranto K, Bates DW. Preventable adverse drug events and their causes and contributing factors: The analysis of register data. Int J Qual Health Care 2011;23(2):187-97.

https://doi.org/10.1093/intqhc/mzq085

66. Mendes W, Pavão AL, Martins M, Moura Mde L, Travassos C. The feature of preventable adverse events in hospitals in the State of Rio de Janeiro, Brazil. Rev Assoc Med Bras 1992 2013;59(5):421-8.

https://doi.org/10.1016/s2255-4823(13)70500-9

67. Wolfe D, Yazdi F, Kanji S, Burry L, Beck A, Butler C, et al. Incidence, causes, and consequences of preventable adverse drug reactions occurring in inpatients: A systematic review of systematic reviews. PLoS One 2018;13(10):e0205426.

https://doi.org/10.1371/journal.pone.0205426

\section{RELATED ARTICLES PUBLISHED IN JHSCI}

1. Ilievová Lubica, Žitný P, Jakobejova J. The association between the quality of life and depression of elderly in a nursing home institutional setting. JHSCI. 2016;6(3):162-7.

2. Mahmutovic J, Rudić A, Pašalić A, Jusupović F, Branković $S$, Jaganjac A. Risk factors for depression in residents of gerontology center in Sarajevo. JHSCI. 2015;5(1):19-24.

3. Miškulin M, Kristić M, Vlahović J. Vitamin B12 deficiency and depression in elderly: cross-sectional study in Eastern Croatia. JHSCI. 2014;4(3):143-8. 